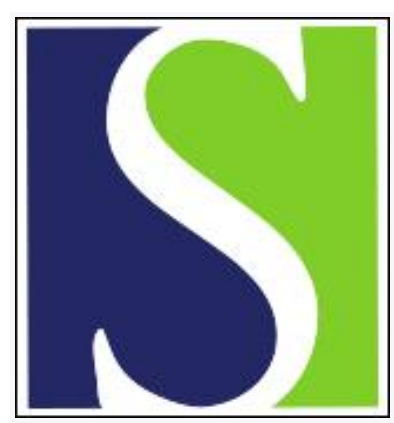

Scand J Work Environ Health 2004;30(4):313-321

https://doi.org/10.5271/sjweh.800

Issue date: Aug 2004

Acute respiratory effects of exposure to ammonia on healthy subjects

by Sundblad B-M, Larsson B-M, Acevedo F, Ernstgård L, Johanson G, Larsson K, Palmberg L

Affiliation: Lung and Allergy Research, National Institute of Environmental Medicine, Kalolinska Institute, S-171 77 Stockholm, Sweden. Britt-Marie.Sundblad@imm.ki.se

Key terms: acute respiratory effect; ammonia; bronchial responsiveness; exposure; human; inflammation; respiratory effect; symptom

This article in PubMed: www.ncbi.nlm.nih.gov/pubmed/15458015

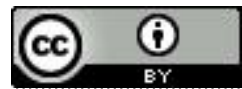




\title{
Acute respiratory effects of exposure to ammonia on healthy persons
}

\author{
by Britt-Marie Sundblad, PhD, ${ }^{1}$ Britt-Marie Larsson, PhD, ${ }^{1}$ Fernado Acevedo, PhD, ${ }^{1}$ Lena Ernstgård, PhD, ${ }^{2}$ \\ Gunnar Johanson, PhD, ${ }^{2}$ Kjell Larsson, PhD, ${ }^{1}$ Lena Palmberg, PhD ${ }^{1}$
}

\author{
Sundblad B-M, Larsson B-M, Acevedo F, Ernstgård L, Johanson G, Larsson K, Palmberg L. Acute respiratory \\ effects of exposure to ammonia on healthy subjects. Scand J Work Environ Health 2004;30(4):313-321.
}

\begin{abstract}
Objectives This study investigated the acute respiratory effects of low ammonia exposure on healthy persons. Methods Twelve healthy persons underwent sham or ammonia (5 and $25 \mathrm{ppm}$ ) exposure randomly in an exposure chamber on three occasions. The exposure duration was 3 hours, 1.5 hours resting (seated) and 1.5 hours exercising ( $50 \mathrm{~W}$ on a bicycle ergonometer). Symptoms were registered repeatedly before, during, and after the exposure on visual analogue scales. Bronchial responsiveness to methacholine, lung function, and exhaled nitric oxide (NO) were measured before and 7 hours after the exposure. In addition, nasal lavage was performed, and peripheral blood samples were drawn before and 7 hours after the exposure.

Results All the symptom ratings increased significantly during 25-ppm ammonia exposure as compared with the control exposure. The cumulative dose of methacholine causing a $20 \%$ decrease in forced expiratory volume in 1 second was lower $(<1$ concentration step of methacholine) for the exposure than for a pretrial control challenge. However, no difference was found between the control and ammonia exposures $(\mathrm{P}=0.33)$. The ammonia exposure did not significantly influence lung function or the exhaled NO levels. The total cell or interleukin- 8 concentration in nasal lavage fluid did not change. The total leucocyte concentration in peripheral blood increased significantly $(\mathrm{P}<0.001)$ after both the sham and ammonia exposure, mainly due to an increase in neutrophils $(\mathrm{P}<0.001)$. Ammonia exposure did not significantly alter complement factor $3 \mathrm{~b}$ in plasma.

Conclusions During ammonia exposure in an exposure chamber, symptoms related to irritation and central nervous effects increase and are constant with no signs of adaptation. Ammonia inhalation does not cause detectable upper-airway inflammation or increased bronchial responsiveness to methacholine in healthy persons.
\end{abstract}

Key terms ammonia, bronchial responsiveness, human, inflammation, symptoms.

Exposure in a swine confinement building causes intense airway inflammation and increased bronchial responsiveness in healthy subjects $(1,2)$. The use of a halfmask with a particle filter during exposure attenuates the inflammatory response but only slightly influences the increase in bronchial responsiveness (3). These results suggest that gases may be responsible for the increase that occurs in bronchial responsiveness after swine house exposure. Ammonia and hydrogen sulfide are present in swine confinement buildings. In our previous studies the levels of hydrogen sulfide were $<0.5$ ppm, which is far below the occupational exposure limit $(10 \mathrm{ppm})(4)$. No influence of hydrogen sulfide on lung function has been shown at these low levels $(5,6)$. The airborne level of ammonia during our previous exposure experiments in a swine confinement building was approximately 10 (range 2-15) ppm.
Ammonia is known as an irritating and toxic substance. The extent of respiratory injury after ammonia inhalation depends on the duration of exposure, the concentration of the gas, and the tidal volume. Acute exposure to high concentrations of ammonia may cause tracheobronchitis with severe airflow obstruction followed by chronic airflow obstruction with bronchiectasis $(7,8)$. It has been suggested that long-term exposure to lower concentrations is associated with sinusitis, mucous membrane inflammation syndrome, chronic bronchitis, and asthma-like symptoms (4).

Earlier studies have revealed disparate results regarding ammonia exposure in swine houses. Heederik et al (9) found no relationship between ammonia exposure and lung function, and this lack of a relationship is in contrast to the results of the study by Preller et al (10), who found an association between ammonia exposure

1 Lung and Allergy Research, National Institute of Environmental Medicine, Karolinska Institutet, Stockholm, Sweden.

2 Work Environment Toxicology, National Institute of Environmental Health, Stockholm, Sweden.

Reprint requests to: Dr Britt-Marie Sundblad, Lung and Allergy Research, National Institute of Environmental Medicine, Karolinska Institutet, S-171 77 Stockholm, Sweden. [E-mail: Britt-Marie.Sundblad@imm.ki.se] 
during a disinfection procedure and lung function in pig farmers. Vogelzang et al (11) found no relationship between exposure to ammonia and bronchial responsiveness in farmers in 1997, but, when a re-examination was conducted 3 years later, the same authors found an increased bronchial responsiveness that was significantly associated with the exposure to ammonia (12).

In order to determine whether ammonia may be responsible to some extent for the health effects following exposure in swine houses, as indicated in the study with respirators, the aim of our study was to monitor health effects before and after controlled exposure to ammonia in a chamber at two different concentrations, one below the Swedish occupational exposure limit (25 ppm) and one identical to it.

\section{Participants and methods}

\section{Participants}

Twelve healthy participants ( 7 women, 5 men), mean age 25 (range 21-28) years, participated in the study. All the subjects denied past and present symptoms of allergy or airway diseases. Atopy was tested with Phadiatope® (Pharmacia, Uppsala, Sweden).

The exposures were carried out after oral and written consent was given by the volunteers. The women performed a pregnancy test, urinary human chorionic gonatropin (Boehringer Mannheim, Italy), immediately before each exposure.

The Ethics Committee of the Karolinska Institutet approved the study.

Table 1. Increase in symptom ratings during exposure to ammonia. The increase was calculated by subtracting the preexposure rating from the average of all ratings during the 3-hour exposure period. (VAS = visual analogue scale)

\begin{tabular}{|c|c|c|c|c|}
\hline \multicolumn{2}{|c|}{ Question } & \multicolumn{3}{|c|}{$\begin{array}{l}\text { Average increase in VAS } \\
\text { rating during exposure (mm) }\end{array}$} \\
\hline & & 0 ppm & 5 ppm & 25 ppm \\
\hline Q1 & $\begin{array}{l}\text { Eye discomfort: burning, } \\
\text { irritated, or running eyes }\end{array}$ & -0.5 & $3.6^{a}$ & $14.8^{a}$ \\
\hline Q2 & $\begin{array}{l}\text { Nose discomfort: burning, } \\
\text { irritated, or runny nose }\end{array}$ & -4.7 & 3.4 & $15.3^{a}$ \\
\hline Q3 & Throat or airway discomfort & -2.9 & 1.2 & $14.2^{\mathrm{a}}$ \\
\hline Q4 & Breathing difficulty & -1.2 & 2.3 & $12.2^{\mathrm{a}}$ \\
\hline Q5 & Solvent smell & 0.2 & $38.1^{\mathrm{a}}$ & $61.8^{a}$ \\
\hline Q6 & Headache & -0.6 & $-0.2^{b}$ & $6.2^{\mathrm{a}}$ \\
\hline Q7 & Fatigue & -8.1 & -5.7 & $2.5^{b}$ \\
\hline Q8 & Nausea & -0.5 & 3.6 & $14.8^{a}$ \\
\hline Q9 & Dizziness & 0.1 & $0.6^{b}$ & $4.4^{\mathrm{a}}$ \\
\hline Q10 & Feeling of intoxication & 0.3 & $0.9^{b}$ & $4.2^{b}$ \\
\hline
\end{tabular}

a Significantly different from 0 ppm in Wilcoxon signed rank test, $P<0.01$. ${ }^{b}$ Significantly different from 0 ppm in Wilcoxon signed rank test, $P<0.05$.

\section{Study design}

The participants were exposed in randomized order to sham or ammonia, $5\left(3.5 \mathrm{mg} / \mathrm{m}^{3}\right)$ and $25\left(17.7 \mathrm{mg} / \mathrm{m}^{3}\right)$ ppm, in an exposure chamber on three different occasions. One to four volunteers were exposed for 3 hours on each occasion. Half of the time they rested (seated), and half of the time they exercised, $50 \mathrm{~W}$ on a bicycle ergometer (Monark ergomedic 829E, Monark Exercise AB, Varberg, Sweden) (changing activity every half hour). The exposures were separated by at least 1 week. Lung function and methacholine challenge were performed 1 week (always in the afternoon, matching the posttrial measurement) before the first exposure day (pretrial measurement). Nasal lavage fluid, blood, and exhaled nitric oxide (NO) were sampled approximately 0.5 hours before the exposure and also at the same time as the lung function measurement and methacholine challenge, 7 hours after the start of exposure. Peak expiratory flow (PEF) and body temperature were measured in the morning before the exposure, immediately after the exposure, and 7 hours after the exposure.

\section{Exposure conditions}

The ammonia exposures were carried out in a $20-\mathrm{m}^{3}$ stainless steel exposure chamber with 18 to 20 air changes per hour. A high-performance liquid chromatography (HPLC) pump (Hitachi L-6200, Tokyo. Japan) transferred an aqueous solution of $25 \%$ (weight/volume) ammonia to a preheated glass tube $\left(90^{\circ} \mathrm{C}\right)$, where the solution was completely vaporized and followed the influent air stream into the exposure chamber (adjusted to actual concentration). The temperature [mean 20.3 (range 18.2-22.1) ${ }^{\circ} \mathrm{C}$ ] and humidity [mean 29 (range 1237 \%] were continuously recorded (Vaisala HMP 36) and logged (Squirrel Meter Logger 1200 Series, Grant, Bromma, Sweden) on a personal computer at 1-minute intervals.

The chamber air was sampled from the upper central part of the chamber, and the ammonia concentration was monitored in the air by infrared spectrophotometry (Miran-80, Foxboro, Milton Keynes, England) with a gas cell (volume 5.1 1). The measurements were carried out at $10.52 \mu \mathrm{m}$ (with $20.25 \mu \mathrm{m}$ as the reference wavelength), and the concentration was recorded every 5 minutes. Standard curves were obtained by injecting known amounts of ammonia directly into the gas cell.

\section{Symptoms}

During the exposure, the participants rated the level of perceived discomfort on a questionnaire with 10 questions in Swedish (table 1), immediately before, during $(3,28,58,88,118,148$ and 178 minutes from the start of exposure), and after (270 minutes from the onset of 
exposure) the exposure. A $0-100 \mathrm{~mm}$ visual analogue scale $(\mathrm{VAS})(0=$ no symptoms, $100=$ severe symptoms $)$ was used for the ratings. The same questionnaire has been used in several chamber inhalation studies performed with organic solvent vapors in our laboratory $(13,14)$.

Such general symptoms as headache, chills, mental fatigue, muscle pain, and malaise were also recorded using the VAS scale, before and 7 hours after the exposure. In addition seven questions about nose- and airway-specific symptoms (sneezing, nasal congestion, nasal secretion, cough, tightness in chest, shortness of breath, and wheezing) were also answered.

\section{Lung function and bronchial responsiveness}

Vital capacity (VC) and forced expiratory volume in 1 second (FEV1) were measured with a wedge spirometer (Vitalograph ${ }^{\circledR}$, Buckingham, UK) and total lung capacity (TLC) with a body plethysmograph (Eric Jaeger GmbH \& Co, Würsberg, Germany) according to recommendations by the American Thoracic Society (ATS) (15). Local reference values were used $(16,17)$. Peak expiratory flow (PEF) was measured using a peak flow meter (Mini-Wright, Clement Clarke International Ltd, London, UK).

Bronchial responsiveness was assessed by a methacholine provocation test. Inhalation of the diluent was followed by inhalation of doubling concentrations of methacholine starting at $0.5 \mathrm{mg} / \mathrm{ml}$. The challenge was stopped at a FEV1 decrease of $20 \%$ compared with the value obtained after inhalation of the diluent or after inhalation of the highest methacholine concentration (32 $\mathrm{mg} / \mathrm{ml}$ ). The results were expressed as the PD20FEV1 (cumulative dose of methacholine causing a 20\% decrease in FEV1). In addition the dose-response slope was calculated using linear regression (18).

\section{Exhaled nitric oxide}

Exhaled NO was determined using single-breath exhalation, and the measurements were performed in accordance with recommendations from the European Respiratory Society (ERS) and ATS $(19,20)$. The subjects inhaled NO-free air via a mouthpiece to total lung capacity, followed immediately by exhalation with a flow rate of approximately $50 \mathrm{ml} / \mathrm{s}$. During the exhalation, an excess pressure was created in the oral cavity, to ensure closure of the velum and prevent contamination of the sample with nasal air. To decrease contamination from the oral cavity, mouthwash with water and sodium bicarbonate (10\%) in 1 minute was done preceding the measurement procedure (21). NO was measured with chemiluminecence after reaction with ozone (NIOX®, Aerocrine, Stockholm, Sweden).

\section{Nasal lavage}

Nasal lavage (NAL) was performed using a procedure described by Bascom et al $(22,23)$ with minor modifications. Five milliliters of $0.9 \%$ sodium chloride $(\mathrm{NaCl})$ was instilled into one nostril, and after 10 seconds the fluid was expelled into a plastic cup. The procedure was repeated in the other nostril, and the lavage samples were pooled. Cells were counted and calculated for the number of cells per milliliter of recovered fluid. Interleukin-6 (IL-6) and IL-8 in nasal lavage fluid was determined in duplicate with the use of a specific enzymelinked immunosorbent assay (ELISA) developed at our laboratory (24) using commercially available antibody pairs (R\&D systems, Europe, Abingdon, UK). For duplicated samples an intraassay coefficient of variation $(\mathrm{CV})$ of $<10 \%$ and an interassay CV of $<20 \%$ was accepted.

\section{Peripheral blood}

Total and differential white blood cell counts of peripheral blood were performed by flow cytometry (FACS Calibur, Becton Dickinson, San Jose, CA, USA). Blood was collected into ethylene diamine tetraacetic acid (EDTA) and incubated with cell surface markers CD45/ CD14 (LeucoGate ${ }^{\mathrm{TM}}$, Becton Dickinson, San Jose, CA, USA) in TRUECOUNTTM absolute count tubes (Becton Dickinson) for 15 minutes at room temperature in darkness. The samples were then hemolyzed using FACS $^{\text {TM }}$ lysing solution (Becton Dickinson) and incubated for 15 minutes at room temperature in darkness and finally analyzed by flow cytometry.

For the analysis of complement factor $\mathrm{C} 3$ and $\mathrm{C} 3 \mathrm{~b}$, the samples $(10 \mu \mathrm{l})$ were separated by isotachophoresis (ITP) in agarose isogel (FMC bioproducts, Rockland, Maryland, USA) as previously described (25). The electrophoresis was run until the ITP front reached the anode. Immediately after the run, the $\mathrm{C} 3$ complement proteins in the gel were precipitated with rabbit antihuman C3c [Dako A/S, Copenhagen, Danmark, diluted 1:1000 in $20 \mathrm{mM}$ hydroxymethyl aminomethane-hydrochloride (Tris- $\mathrm{HCl}), 0.9 \% \mathrm{NaCl}$ pH 7.4 (TBS)] by incubation overnight at room temperature. The gel was washed three times with TBS followed by water, dried under an air stream, and stained with coomassie brilliant blue. The amount of $\mathrm{C} 3$ and $\mathrm{C} 3 \mathrm{~b}$ was calculated from the values obtained from similarly separated dilutions of a serum protein calibrator (Dako A/S, Copenhagen, Denmark). The stained gels were scanned with a desktop scanner (Studio Star ${ }^{\circledR}$ from Agfa-Gevaert NV, Mortsel, Belgium) using a gray scale of 256 values and a resolution of 300 pixels per inch. The data were processed with the program QuantiScan from Biosoft (Cambridge, England). The percentage of $\mathrm{C} 3$ conversion was calculated from the ratio $\mathrm{C} 3 \mathrm{~b} /(\mathrm{C} 3+\mathrm{C} 3 \mathrm{~b})$. 


\section{Statistical analysis}

The results are presented as medians (25th-75th percentiles), except for the lung function values and differences, which are presented as means and standard deviations. Comparisons were performed by means of an analysis of variance (ANOVA) and Student's t-test for paired observations (lung function and blood data). Regarding symptom ratings, all seven time points during the exposure were averaged before the analyses. Wilcoxon signed rank test (StatView, v 5, SAS Institute Inc, Cary, NC, USA) was used to test for the differences in symptom ratings, exhaled NO, bronchial responsiveness, and nasal lavage between the exposure conditions. Trend analyses were made by using the Friedman test (StatView, v 5, SAS Institute Inc, Cary, NC, USA). The Spearman rank correlation test (JMP, v 4.02, SAS Institute Inc, Cary, NC, USA) was used to test for the correlation between the ratings.

A P-value of $<0.05$ (or $<0.01$ when multiple comparisons were performed) was considered significant.

\section{Results}

\section{Symptoms}

All 10 symptom ratings were significantly higher during the exposure to $25 \mathrm{ppm}$ of ammonia than during the sham exposure (table 1). At $5 \mathrm{ppm}$, discomfort in the eyes (figure 1), solvent smell (figure 2), headache, dizziness, and feeling of intoxication were significantly increased.

In general, there was a weak and nonsignificant correlation $($ rho $<0.4)$ between the rating of smell and other ratings. Furthermore, the correlation between the ratings mainly related to irritation $(\mathrm{Q} 1-$ Q4) and those mainly related to central nerve system (CNS) effects (Q6-Q10) was low (rho mostly $<0.5)$. In contrast, the ratings of related symptoms were highly correlated. For example the rho was 0.97 for Q9 versus Q10.

The average rating of irritation and the CNS symptoms during exposure to ammonia did not exceed the rating corresponding to "rather" $(48 \mathrm{~mm})$. The average ratings before and after the exposure did not exceed

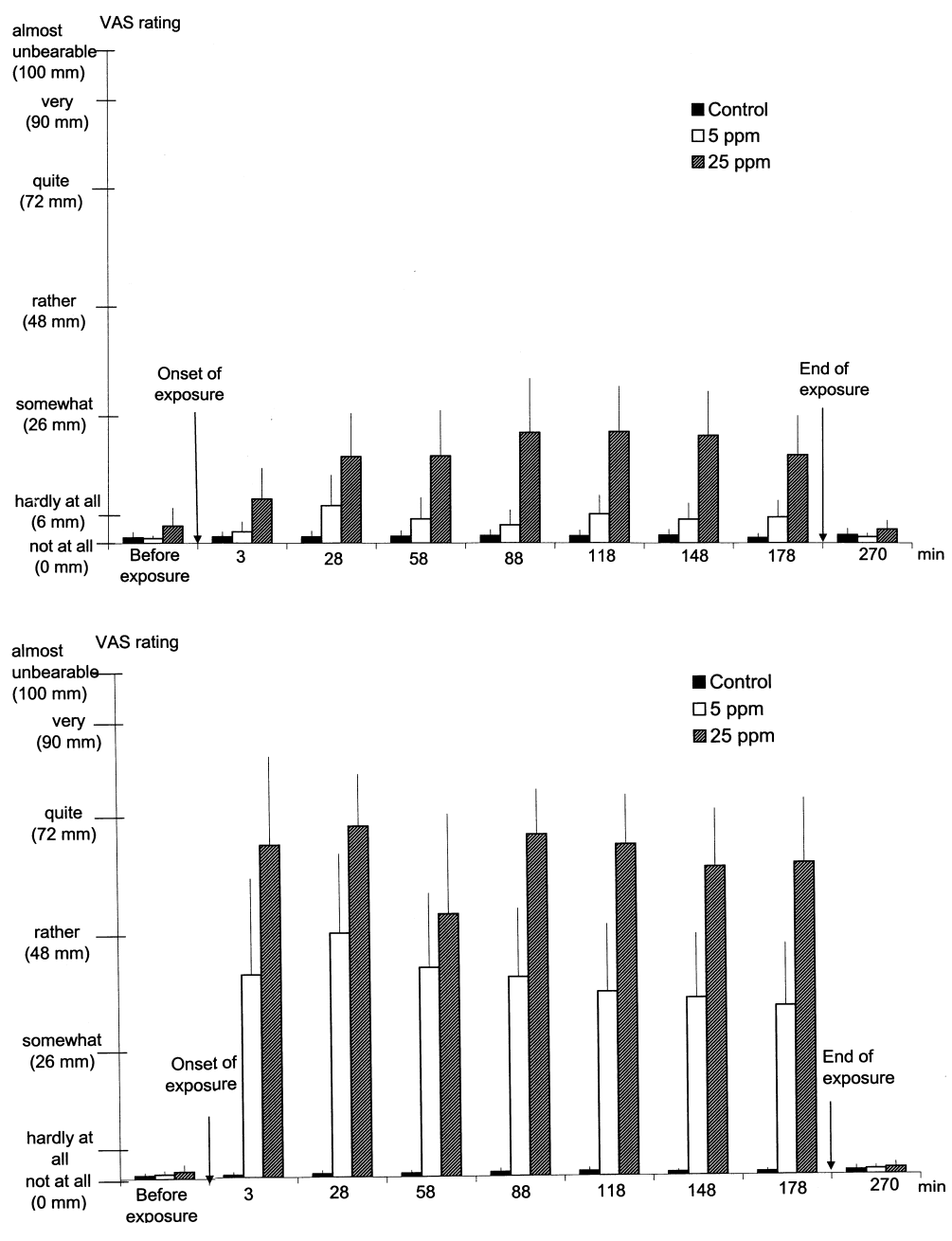

Figure 1. Average ratings of eye discomfort: burning, irritated, or running eyes $(\mathrm{N}=12)$. The upper $95 \%$ confidence limits (vertical lines) are indicated to illustrate the variability of the responses.
Figure 2. Average ratings of solvent smell $(\mathrm{N}=12)$. The upper $95 \%$ confidence limits (vertical lines) are indicated to illustrate the variability of the responses. 
"hardly at all" (6 mm), except for the ratings of fatigue (13 mm immediately before and $23 \mathrm{~mm} 1.5$ hours after the exposure).

Regarding airway-specific symptoms, three participants experienced increased secretion from the nose, and two reported increased cough after exposure to the highest concentration of ammonia (25 ppm). No other symptoms were reported 7 hours after the exposure.

The oral temperature did not increase significantly at any of the three exposure levels.

\section{Lung function and bronchial responsiveness}

The pretrial lung function was normal for all the participants [TLC 95 (SD 9)\%, VC 96 (SD 10)\% and FEV1 102 (SD 9)\% of the predicted value]. The exposure did not influence either the lung function values or the PEF significantly (table 2).

The pretrial PD20FEV1 was 1.91 (0.92-12.6) $\mathrm{mg}$. The PD20FEV1 was $1.72(0.46-3.26) \mathrm{mg}$ after the sham exposure and $0.95(0.49-4.06) \mathrm{mg}$ and $1.52(0.88-2.31)$ $\mathrm{mg}$ after the 5- and 25-ppm ammonia exposure, respectively (figure 3 ). There were significant differences in the PD20FEV1 when the pretrial and each of the postexposure values $(0,5$, and $25 \mathrm{ppm})$ were compared ( $\mathrm{P}=0.05, \mathrm{P}=0.003$, and $\mathrm{P}=0.03$, respectively). However, the change in PD20FEV1 was less than 1 concentration step below the pretrial values for all three exposures. There were no differences when the exposure to fresh air $(0 \mathrm{ppm})$ was compared with the exposure to 5 and $25 \mathrm{ppm}$ of ammonia $(\mathrm{P}=0.79$ and $\mathrm{P}=0.58$, respectively).

\section{Exhaled nitric oxide}

The pretrial exhaled NO levels were normal for all the participants, $11.6(6.0-17.9) \mathrm{ppb}$. There were no significant differences in the exhaled NO when the pretrial values were compared with those of the sham exposure [1.20 (SD 3.5) ppb] or the 5-ppm [-0.81 (SD 1.27) ppb], and 25-ppm [0.26 (SD 1.42) ppb] ammonia exposure ( $\mathrm{P}=0.12)$.

Table 2. Lung function before and 7 hours after exposure. (VC = vital capacity; TLC = total lung capacity; FEV1 = forced expiratory volume in 1 second; $P E F$ = peak expiratory flow, mean value of three measurements at three different time points)

\begin{tabular}{|c|c|c|c|c|c|c|c|c|c|}
\hline \multirow[t]{3}{*}{ Lung function } & \multirow{2}{*}{\multicolumn{2}{|c|}{ Before exposure }} & \multicolumn{6}{|c|}{ After exposure } & \multirow[t]{3}{*}{$\mathrm{P}$-value } \\
\hline & & & \multicolumn{2}{|c|}{$0 \mathrm{ppm}$} & \multicolumn{2}{|c|}{5 ppm ammonia } & \multicolumn{2}{|c|}{25 ppm ammonia } & \\
\hline & Mean & SD & Mean & SD & Mean & SD & Mean & SD & \\
\hline VC (I) & 4.90 & 0.91 & 4.94 & 0.95 & 4.96 & 0.93 & 4.92 & 0.95 & 0.79 \\
\hline TLC (I) & 6.18 & 1.05 & 6.26 & 1.14 & 6.15 & 1.12 & 6.28 & 1.08 & 0.11 \\
\hline FEV1 (I) & 4.25 & 0.69 & 4.25 & 0.76 & 4.23 & 0.75 & 4.26 & 0.73 & 0.95 \\
\hline PEF (I/min) & & & 557 & 90 & 557 & 84 & 561 & 92 & 0.94 \\
\hline
\end{tabular}

a Comparison between the different conditions (analysis of variance).
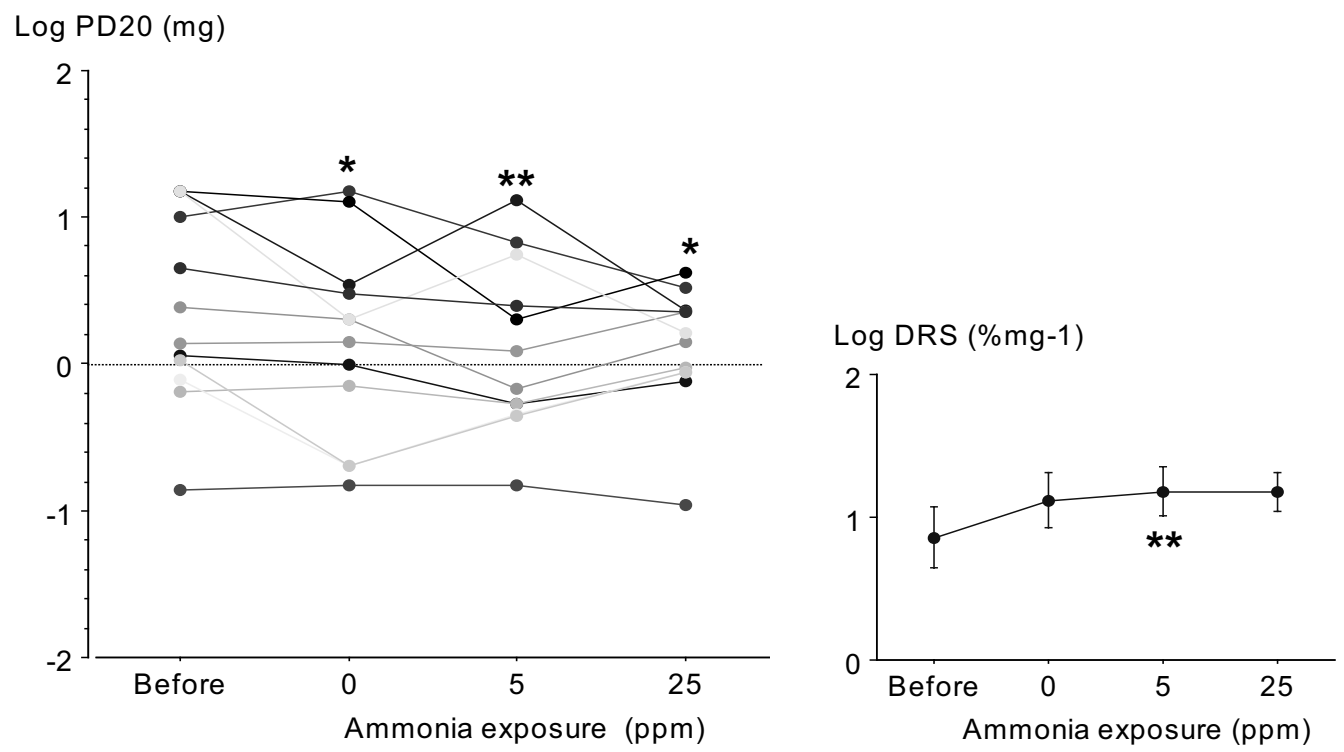

Figure 3. Bronchial responsiveness to methacholine before and after exposure to ammonia. Data are presented as PD20FEV1 (individual values) and the dose-response slope (median values) $(\mathrm{N}=12)$ : ${ }^{*} \mathrm{P}<0.05,{ }^{*} \mathrm{P}<0.01$ compared with the preexposure value. There were no significant differences when 5- and 25-ppm ammonia exposure were compared with the sham exposure. (PD20FEV1 = cumulative dose of methacholine causing a $20 \%$ decrease in forced expiratory volume in 1 second) 


\section{Nasal lavage analysis}

No significant increase in the total cell concentration of the nasal lavage fluid occurred after exposure to ammonia $(\mathrm{P}=0.21)$ (figure 4). The concentration of IL-8 did not change significantly after the exposure to the highest concentration of ammonia, compared with the results of the control exposure with fresh air ( $\mathrm{P}=0.92)$. IL-6 in the nasal lavage fluid was below the detection limit after the exposure to $25 \mathrm{ppm}$ of ammonia.

\section{Blood analyses}

The concentration of total leucocytes in blood had increased significantly after all three exposure occasions $(\mathrm{P}<0.001)$, mainly due to an increase in neutrophilic granulocytes $(\mathrm{P}<0.001)$ (figure 4$)$. The number of monocytes, lymphocytes, basophilic granulocytes, and eosinophils did not change significantly, and there was no significant difference in the cell increase between the

\section{Peripheral blood}

Neutrophilic granulocytes $\times 10^{9} / \mathrm{L}$

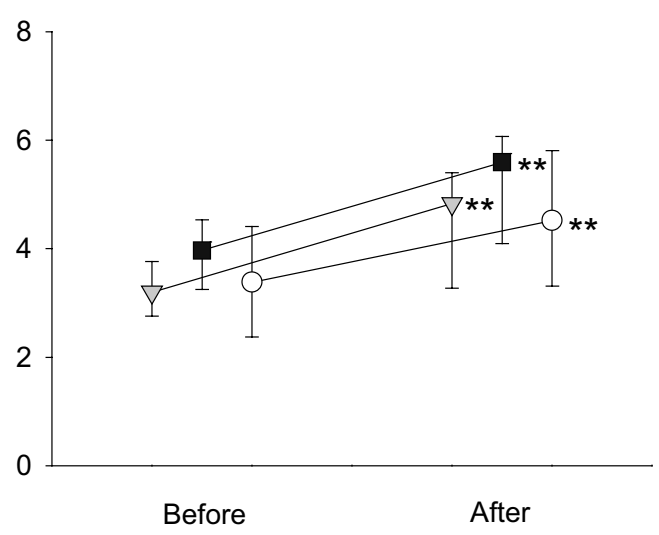

Nasal lavage

Total cell concentration $\times 10^{6} / \mathrm{L}$

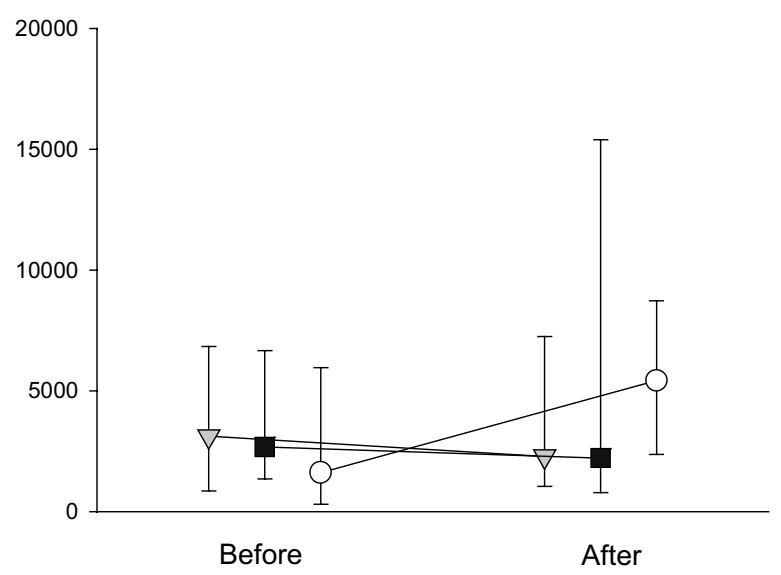

sham exposure and the 5- and 25-ppm ammonia exposure.

The ammonia exposure did not significantly alter $\mathrm{C} 3 \mathrm{~b}$ in plasma. The level of C3b was $6.1(1.3-8.9) \%$ of the total $\mathrm{C} 3$ before the exposure and $7.6(4.2-12.0) \%$ after the exposure to the highest concentration of ammonia $(\mathrm{P}=0.09)$.

\section{Discussion}

Our study showed that the inhalation of ammonia (5 and $25 \mathrm{ppm}$ ) causes symptoms but no inflammatory reaction in the upper airways, no alteration in the levels of exhaled NO, and no alteration in bronchial responsiveness to methacholine in healthy persons.

Although the levels of ammonia were below or identical to the hygienic threshold limit (25 ppm) the

$$
\text { Monocytes } \times 10^{9} / \mathrm{L}
$$



Figure 4. Cell concentrations (median and 25th and 75th percentiles) in peripheral blood (neutrophilic granulocyte and monocytes) and nasal lavage (total cell concentration) before and after ammonia exposure. There were no significant differences between the sham exposure and the 5 - and $25-p p m$ ammonia exposure. ${ }^{* * *} P<0.001$, ** $P<0.01$.) 
participants reported increased symptoms during exposure in the exposure chamber. The ratings of irritation and CNS effects were all significantly higher during exposure to $25 \mathrm{ppm}$ of ammonia than during the control exposure. With $5 \mathrm{ppm}$ of ammonia some of the ratings (discomfort of the eyes, solvent smell, headache, dizziness, and feeling of intoxication) were significantly increased. Furthermore, for all the ratings except "fatigue" and "feeling of intoxication", there was a clear and significant dose-response relationship.

The high correlation between similar types of symptoms and the weak correlation between different types of symptoms and between symptoms and smell indicate that the subjects discriminated between symptoms and that the ratings did not merely reflect awareness of exposure. The fact that exposure with smelly gases like ammonia cannot be blinded may have possibly influenced the symptom ratings.

No sensory adaptation was apparent at $25 \mathrm{ppm}$ of ammonia, as judged by the rating of smell. However, at 5 ppm a tendency towards adaptation was observed. In a previous study using the same VAS questionnaire, a sensory adaptation to solvent smell was observed during exposure to n-butyl acetate (26). We have also observed a similar adaptation during exposure to 2-propanol, $m$-xylene, toluene, acetone, methyl tertiary-butyl ether, ethyl tertiary-butyl ether, 1,2,4-trimethylbenzene, 1,2,3-trimethylbenzene, and 1,3,5-trimethylbenzene (unpublished observations).

The symptom ratings indicate an irritating effect of ammonia at 5 and $25 \mathrm{ppm}$. The increase in the ratings was significant at $25 \mathrm{ppm}$ and persisted throughout the 3 hours of exposure. The increases in the irritation rating reached about one-third of the VAS, corresponding to a verbal rating of between "somewhat" and "rather". This finding indicates a need to reconsider the present occupational exposure limits of 25 ppm [eg, Sweden (27), and American Conference of Governmental Industrial Hygienists, (28)] and 20 ppm [eg, Germany (29)].

A small (less than one concentration step of methacholine) but significant postexposure increase in bronchial responsiveness was observed after all the exposures when the results were compared with pretrial values, and the change in the dose-response slope was only significant after 5-ppm exposure. The change in bronchial responsiveness seems to be explained by the results of a few persons, and the basal values of these participants were not distinguished from the others. This increase in bronchial responsiveness is probably not an effect of exposure since sham exposures yielded the same result as ammonia. It is more an effect induced by staying in the exposure chamber or performing exercise there. Exercise in dry and cold air causes transient narrowing of the airways in asthmatic persons (30). However, all of our participants were healthy and denied having ever experienced exercise-induced airway symptoms. The temperature inside and outside the chamber was about $20^{\circ} \mathrm{C}$ on all the exposure occasions, whereas the humidity differed from $12 \%$ to $37 \%$ over time. It is unlikely that the variation in humidity influenced the bronchial responsiveness 4 hours after the exposure, when the methacholine tests were performed.

The significant increase in the number of neutrophilic granulocytes in blood after the three different exposures is probably not an effect of exposure but rather an effect induced by the exercise in the exposure chamber. Granulocytosis following exercise has previously been demonstrated (31).

Swine dust exposure causes an inflammatory reaction characterized by a massive influx of neutrophils and other inflammatory cells, as well as the release of inflammatory mediators and cytokines in the upper and lower airways $(32,33)$. No alteration of cell number or mediator levels in nasal lavage fluid and peripheral blood in association with ammonia exposure was found in our study. Furthermore, the unchanged levels of exhaled NO after exposure suggest that no inflammatory reaction occurred in the lower airways. These findings probably exclude ammonia as the sole cause of the airway inflammation observed in healthy persons following exposure in swine houses (1). In a previous study, we found indications that exposure in swine confinement buildings causes an activation of human plasma complement factor 3 . We had reason to believe that ammonia or other gases were possible candidates for that activation $(34,35,36)$. The wearing of a respiratory protection device with a particle filter during swine dust exposure had no effect on complement activation, a minor effect on increased bronchial responsiveness, but a dramatic effect on the inflammatory airway response (3). Since the exposure did not induce any significant change in $\mathrm{C} 3 \mathrm{~b}$ in plasma, ammonia did not activate the complement in this study. Therefore, the findings in the previous study with mask protection and the results in our present study suggest that gases other than ammonia or ultrafine particles may be responsible for activating the complement and increasing bronchial responsiveness in this environment. Furthermore, we cannot exclude the leakage of particles for very short time periods during the exposure, and such leakage may particularly influence bronchial responsiveness.

Our results are in accordance with those of Heederik et al (9), who did not find a relationship between ammonia exposure and the lung function of swine farmers (9). However, the ammonia exposure level of pig farmers [2.4 (SD 2.3) ppm] was shown to be significantly 
associated with baseline lung function (10), and the association with bronchial responsiveness was stronger for symptomatic farmers (12). In a soda ash plant, where the workers were exposed to the same levels of ammonia as in our swine house [9.2 SD 1.4) ppm], no difference regarding baseline lung function or workshift change was reported in a comparison with the results of a control group (37). In another study, workers in an ammonia factory were compared with a control group, and only the workers exposed to high cumulated levels of ammonia ( $>50 \mathrm{mg} / \mathrm{m}^{3}$ annually) showed a reduced lung function (38). On the whole, there are many reports of acute human accidental exposures to inhaled ammonia, but it is difficult to find studies measuring the health effects of long-term and low-exposure concentrations of ammonia (39).

Ammonia exposure in an exposure chamber can be more continuous at the same levels than in workplaces, where high exposure peaks can occur. However, when the ammonia concentration was continuously measured every minute in a swine confinement building, only some very short and low peaks were registered (unpublished observations). Therefore, in our study, chamber exposure may correspond to workplace exposure to ammonia.

Ammonia is hygroscopic, and in free form, as in our experiments, it will mostly be absorbed in the upper part of the respiratory tract. However, it has been suggested that dust particles can act as carriers that may bring ammonia into smaller airways. Particles in livestock buildings are relatively large, but smaller inhaled particles cannot be excluded. In addition ammonia may cooperate with other agents, such as dust particles, in farming environments and then cause the effects on the airways observed after swine dust exposure. Therefore, the disparate association between ammonia exposure and airway effects can be due to the duration and form of the ammonia exposure, and also to whether or not the exposed persons are healthy or symptomatic.

In conclusion, exposure to 5 and $25 \mathrm{ppm}$ of ammonia had transient effects on irritating and CNS symptoms during 3 hours of exposure, and therefore a revision of the occupational exposure limit should be considered. However, there were no specific airway effects after exposure to these levels of ammonia.

\section{Acknowledgments}

The Swedish Farmer Foundation and The Swedish Heart and Lung Foundation supported this study.

We thank Dr A Iregren for his valuable comments on the evaluation of the symptom ratings.

\section{References}

1. Larsson K, Eklund A, Hansson L, Isaksson B-M, Malmberg P. Swine dust causes intense airways inflammation in healthy subjects. Am J Respir Crit Care Med 1994;150:973-77.

2. Malmberg P, Larsson K. Acute exposure to swine dust causes bronchial hyperresponsiveness in healthy subjects. Eur Respir J 1993;6:400-4.

3. Sundblad B-M, Larsson B-M, Palmberg L, Larsson K. Exhaled nitric oxide and bronchial responsiveness in healthy subjects exposed to organic dust. Eur Respir J 2002;20:42631.

4. von Essen S, Donham K. Illness and injury in animal confinement workers. Occup Med 1999;14:337-50.

5. Jäppinen $P$, Vilkka V, Marttila $O$, Haahtela T. Exposure to hydrogen sulphide and respiratory function. $\mathrm{Br} \mathrm{J}$ Ind Med 1990;47:824-28.

6. Bhambhani Y, Burnham R, Snydmiller G, MacLean I, Lovlin R. Effects of 10-ppm hydrogen sulfide inhalation on pulmonary function in healthy men and women. J Occup Environ Med 1996;38(10):1012-17.

7. Leduc D, Gris P, Lheureux P, Gevenois P, De Vuyst P, Yernault J. Acute and long term respiratory damage following inhalation of ammonia. Thorax 1992;47:755-57.

8. de la Hoz R, Schlueter D, Rom W. Chronic lung disease secondary to ammonia inhalation injury: a report on three cases. Am J Ind Med 1996;29(2):209-14.

9. Heederik D, Brouwer R, Biersteker K, Boleij J. Relationship of airborne endotoxin and bacteria levels in pig farms with the lung function and respiratory symptoms of farmers. Int Arch Occup Environ Health 1991;62(8):595-601.

10. Preller L, Heederick D, Boleij J, Vogelzang P, Tielen M. Lung function and chronic respiratory symptoms of pig farmers: focus on exposure to endotoxins and ammonia and use of disinfectants. Occup Environ Med 1995;52:654-660.

11. Vogelzang P, van der Gulden J, Preller L, Tielen J, van Schayck CHF. Bronchial hyperresponsiveness and exposure in pig farmers. Int Arch Occup Environ Health 1997;70:32733.

12. Vogelzang P, van der Gulden J, Folgering H, Heederick D, Tielen M, van Schayck C. Longitudinal changes in bronchial responsiveness associated with swine confinement dust exposure. Chest 2000;117:1488-95.

13. Järnberg J, Johansson G, Löf A. Toxicokenetics of inhaled trimethylbenzenes in man. Toxicol Appl Pharmacol 1996;140:281-8.

14. Ernstgård L, Gullstrand E, Johansson G, Löf A. Toxicokinetic interactions between orally ingested chlorzoxazone and inhaled acetone or toluene in male volunteers. Toxicol Sci 1999;48:189-96.

15. ATS. Standardization of spirometry. Am J Respir Crit Care Med 1995;152:1107-36.

16. Hedenström H, Malmberg P, Agarwal K. Reference values for lung function tests in females: regression equations with smoking variables. Bull Eur Physiopathol Respir 1985;21:551-57.

17. Hedenström H, Malmberg P, Fridriksson HV. Reference values for pulmonary function tests in men: regression equations which include tobacco smoking variables. Upsala J Med Sci 1986;91:299-310.

18. Malmberg P, Larsson K, Thunberg S. Increased lung deposition and biological effect of methacholine by use of drying device for bronchial provocation tests. Eur Respir J 1991;4:890-8. 
19. Kharitonov S, Alving K, Barnas PJ. Exhaled and nasal nitric oxide measurements: recommendations. Eur Respir J 1997;10:1683-93.

20. ATS. Recommendations for standardized procedures for the online and offline measurement of exhaled lower respiratory nitric oxide and nasal nitric oxide in adults and children1999. Am J Respir Crit Care Med 1999;160:2104-17.

21. Zetterquist W, Pedroletti C, Lundberg JON, Alving K. Salivary contribution to exhaled nitric oxide. Eur Respir J 1999;13:327-33.

22. Bascom R, Pipkorn U, Lichtenstein L, Naclerio R. The influx of inflammatory cells into nasal washings during the late response to antigen challenge. Am Rev Respir 1988;138:40612.

23. Pipcorn U, Karlsson G, Enerbäck L. A brush method to harvest cells from the nasal mucosa for microscopic and biochemical analysis. J Immunol Methods 1988;112:37-42.

24. Larsson K, Tornling G, Gavhed D, Muller-Suur C, Palmberg L. Inhalation of cold air increases the number of inflammatory cells in the lungs in healthy subjects. Eur Respir J 1998;12(4):825-30.

25. Acevedo F. Simple quantification of complement factors C3 and C3b using separation by isotachophoresis. Electrophoresis 1999;20:469-72.

26. Iregren A, Löf A, Toomingas A, Wang Z. Irritation effects from experimental exposure to n-butyl acetate. Am J Ind Med 1993;24:727-42.

27. Provisions and General Recommendations. Ordinance AFS 2000:3. Stockholm: Swedish Work Environment Authority (SWEA); 2000. 3.

28. American Conference of Governmental Industrial Hygienists (ACGIH). Documentation of the threshold and biological exposure indices. Cincinnati (OH): ACGIH, 2002.

29. Forchungsgemeinschaft D. MAK-und-BAT-Werte-Liste. Germany: Forchungsgemeinschaft D; 2002.
30. Anderson S. Issues in exercise-induced asthma. J Allergy Clin Immunol 1985;76:763-72.

31. Hansen J, Wilsgard L, Osterud B. Biphasic change in leukocytes induced by stenuous exercise. Eur J Appl Physiol Occup Physiol 1991;62(3):157-61.

32. Larsson B-M, Palmberg L, Malmberg PO, Larsson K. Effect of exposure to swine dust on levels of IL-8 in airway lavage fluid. Thorax 1997;52:638-42.

33. Wang Z, Larsson K, Palmberg L, Malmberg P, Larsson P, Larsson L. Inhalation of swine dust induces cytokine release in the upper and lower airways. Eur Respir J 1997;10:38187.

34. Reid KBM. Classical pathway of activation. In: Rother K, Hänssch GE, editors. The complement system, TG. Heidelberg (Germany): Springer Verlag; 1998. p 68-85.

35. Reid KBM. Lectin pathway of non-self recognition. In: Rother K, Hänssch GE, editors. The complement system, TG. Heidelberg (Germany): Springer Verlag; 1998. p 86-92.

36. Pangburn MK. Alternative pathway, activation and regulation. In: Rother K, Hänssch GE, editors. The complement system, TG. Heidelberg (Germany): Springer Verlag; 1998. p 93-115.

37. Holness L, Purdham J, Nethercott J. Acute and chronic respiratory effects of occupational exposure to ammonia. Am Ind Hyg Assoc J 1989;50:646-50.

38. Ali B, Ahmed H, Ballal S, Albar A. Pulmonary function of workers exposed to ammonia: a study in the Eastern Province of Saudi Arabia. Int J Occup Environ Health 2001;7(1):1922.

39. Swotinsky R, Chase K. Health effects of effects of exposure to ammonia: scant information. Am J Ind Med 1990;17(4):515-21.

Received for publication: 27 November 2003 